\title{
Specificity of TAS-ELISA for Beet Necrotic Yellow Vein Virus and Its Application for Determining Rhizomania Resistance in Field-Grown Sugar Beets
}

\author{
G. C. Wisler, R. T. Lewellen, J. L. Sears, H.-Y. Liu, and J. E. Duffus, USDA-ARS, Salinas, CA
}

\begin{abstract}
Wisler, G. C., Lewellen, R. T., Sears, J. L., Liu, H.-Y., and Duffus, J. E. 1999. Specificity of TAS-ELISA for beet necrotic yellow vein virus and its application for determining rhizomania resistance in field-grown sugar beets. Plant Dis. 83:864-870.

Levels of beet necrotic yellow vein virus (BNYVV), as measured by triple-antibody sandwichenzyme-linked immunosorbent assay (TAS-ELISA), were compared with biological evaluations in representative commercial and experimental sugar beet cultivars developed for production in the United States and ranging in their reactions to rhizomania from uniformly susceptible to highly resistant. TAS-ELISA was specific for BNYVV and did not react with related soilborne sugar beet viruses. Differences in absorbance $\left(A_{405 \mathrm{~nm}}\right)$ values measured in eight cultivars closely correlated with the dosage and frequency of the $R z$ allele, which conditions resistance to BNYVV. A diploid $(R z r z)$ hybrid had a significantly lower absorbance value (less virus) than a similar triploid (Rzrzrz) hybrid. Cultivars that segregated (Rzrz:rzrz) had higher absorbance values than uniformly resistant $(R z r z)$ hybrids, as was expected. For all cultivars, absorbance values decreased as the season progressed. Absorbance value was significantly positively correlated with rhizomania disease index score and negatively correlated with individual root weight, plot root weight, and sugar yield. This information should be useful in resistance-breeding and -evaluation programs and in the sugar industry when considering cultivar choice, inoculum production, and future crop rotations.
\end{abstract}

Additional keywords: beet soilborne mosaic virus, Polymyxa betae, western blot

Rhizomania of sugar beet (Beta vulgaris L.) is an economically important disease caused by the beet necrotic yellow vein furovirus (BNYVV). The virus is vectored by the protist-like fungus Polymyxa betae $(5,16)$, which survives in infested soil for many years in thick-walled fungal resting structures called cystosori $(1,2)$. Typical symptoms of rhizomania include a constricted taproot resulting in a "wineglass" shape, with a proliferation of feeder roots ("bearding") that appear brown due to infestation by darkly colored cystosori and root cell death. Severely infected taproots show necrosis in the vascular system, and roots can be destroyed, which can result in plant death $(7,21)$. Even in moderate rhizomania infestations, sugar content and root yield are depressed. Foliar symptoms associated with an impaired root system include chlorotic patches in the field,

Corresponding author: G. C. Wisler E-mail: gwisler@pwa.ars.usda.gov

The mention of firm names or trade products does not imply endorsement or recommendation by the U.S. Department of Agriculture over other firms or similar products not mentioned.

Accepted for publication 17 May 1999.

Publication no. D-1999-0628-02R

This article is in the public domain and not copyrightable. It may be freely reprinted with customary crediting of the source. The American Phytopathological Society, 1999. which may correspond to movement of soil by cultivation equipment. The necrotic yellow vein of the leaf, for which the virus is named, is rarely seen in the field.

Methods of controlling rhizomania include avoidance of infested fields by testing soil for BNYVV prior to planting, fumigation or solarization of soil where permitted, and use of resistant cultivars (15). A wide range of sugar beet cultivars has been developed with varying degrees of resistance, or tolerance, to rhizomania. Previous reports in England $(3,4)$ and the Netherlands (21) showed that sugar beet cultivars with different levels of resistance correlate with levels of BNYVV detected in roots. Because infected lateral roots remain in the soil after harvest and viruliferous cystosori survive until the next crop is planted, it is important to plant cultivars that do not contribute to increasing levels of BNYVV.

Rhizomania was first recognized in the United States in 1983 in Paso Robles, CA (7). Since then, the disease has become widespread throughout California $(22,23)$ and, subsequently, in other beet-growing states $(6,23,24,26)$. Growers have been reluctant to plant rhizomania-resistant seed because of lower yields and resistance to other diseases initially were associated with these cultivars. However, in newly infested areas, growers have begun using rhizomania-resistant cultivars because recently developed resistant cultivars have the yield potential of nonresistant cultivars and are suited to their production conditions.
Resistance to rhizomania in most commercial sugar beet cultivars is conditioned by the dominant allele, $R z$ (13), as well as by quantitative factors (12) that appear to modify the expression of $R z$. A number of cultivars with varying degrees of resistance to rhizomania based on different genetic backgrounds have been developed for the diverse production conditions found throughout the United States. $R z$ allele dosage (number of alleles in a genotype or individual) and frequency (ratio of $R z$ to $r z$ alleles in a cultivar) are important in the overall performance of sugar beet cultivars under conditions favorable to rhizomania infestation.

One objective of our study was to develop an enzyme-linked immunosorbent assay (ELISA) test that would differentiate a wide range of BNYVV levels in infected roots and would not cross-react with other furoviruses infecting sugar beet, causing misdiagnosis of BNYVV (24). Information regarding different levels of BNYVV in resistant cultivars is important for the sugar industry and breeding programs in selecting resistant cultivars with the lowest levels of BNYVV, which may affect the buildup of rhizomania in soils and give the highest protection.

A second objective was to determine relative levels of BNYVV in representative commercial and experimental sugar beet cultivars and to relate BNYVV levels to the allelic dosage of the cultivars. Cultivars selected ranged in their reactions to rhizomania from uniformly susceptible to resistant. Selection of rhizomania-resistant parental lines for hybrid cultivars is based on field performance, including symptom evaluation, and on analyses for sugar content and root yield (11). In Europe, selections commonly are made based on virus content, as determined by ELISA tests, in sugar beet seedlings grown under controlled conditions in greenhouses and growth rooms (18).

\section{MATERIALS AND METHODS}

Sugar beet cultivars. Cultivars were chosen to represent two geographically diverse growing areas in California and southern Minnesota (Table 1). Identical seed lots of all eight cultivars were grown throughout the study. Cv. USH11, an obsolete commercial hybrid formerly grown throughout California, is highly susceptible to rhizomania and is used routinely in rhizomania studies as a susceptible check. Triploid cv. KWS6770 also is susceptible to rhizomania and has been grown extensively in the upper mid- 
western United States. Cv. Beta4776R is diploid, and each plant is believed to carry one dose of the $R z$ allele $(R z r z)$ derived from a cross of a $R z R z$ parental line with a $r z r z$ line. Beta4776R is widely grown in California. Cv. Beta4038R is a triploid hybrid with the same homozygous diploid source of resistance to rhizomania as Beta4776R and, likewise, carries a single dose of the $R z$ allele but is genotypically Rzrzrz. Beta4038R is grown in the upper midwestern United States and the eastern slope of the Rocky Mountains. Cv. HM7072 is being tested for production in the same areas as Beta4038R and is a diploid hybrid in which each plant carries a single copy of the $R z$ allele. Cv. Rival has wide adaptation; in addition to carrying the $R z$ allele, it also is reputed to have rhizomania resistance from widely grown cv. Rizor. Cv. SS-781R is diploid, and each plant originally was thought to carry one copy of the $R z$ allele, but it now is thought to segregate for $\approx 12 \%$ susceptible ( $r z r z$ ) plants (R. T. Lewellen, unpublished data). SS-781R has been an important cultivar in California in rhizomania-infested areas, particularly in the San Joaquin Valley. Cv. $6921 \mathrm{H} 50$ is an experimental hybrid developed by the USDA-ARS at Salinas, CA, that carries $<50 \%$ frequency of both the $R z$ allele and resistance of unknown inheritance from $B$. vulgaris subsp. maritima sources $(11,14)$.

Serological analysis of BNYVV. Previous studies have shown that in ELISA and western blot analyses polyclonal antisera to BNYVV cross-react slightly with beet soilborne mosaic virus (BSBMV), another furovirus infecting sugar beet $(22,23)$. Crossreactivity is found whether antiserum is prepared to the purified virions or capsid protein (CP) expressed in vitro (25) (Fig. 1). The different molecular mass of the BNYVV $\mathrm{CP}(\approx 22 \mathrm{kDa})$ compared with that of BSBMV $(\approx 24 \mathrm{kDa})$, however, allows for definitive differentiation of the two viruses in western blot assays (Fig. 1A). Monoclonal antibodies produced to BNYVV (provided by $\mathrm{L}$. Torrance and G. Grassi) and antiserum prepared to the $\mathrm{C}$-terminal one-third of BNVYY CP (provided by K. Richards) show complete specificity to all BNYVV isolates tested in both ELISA and western blot assays (23) (Fig. 1; Table 2).

Although western blot analysis provides conclusive distinction between BNYVV and BSBMV, the large numbers of samples to be assayed and the need for quantitation of BNYVV necessitated the use of ELISA tests for our study. A triple-antibody sandwich (TAS) ELISA was developed in collaboration with Agdia Inc. (Elkhart, IN) that was specific for BNYVV, with no cross-reactions with BSBMV isolates (Table 2), and able to obtain a wide range of absorbance values for BNYVV. Serial dilutions of BNYVV-infected leaf and root tissues showed a decrease in absorbance readings that corresponded to decreased concentrations of expressed plant sap (data not shown). Previous
Table 1. Sugar beet hybrids evaluated in rhizomania experiments (Salinas, CA, 1997 growing season)

\begin{tabular}{llll}
\hline Hybrid & Source & Description & Genotype \\
\hline USH11 & USDA-ARS & Diploid susceptible & $r z r z$ \\
KWS6770 & Betaseed & Triploid susceptible & $r z r z r z$ \\
Beta4776R & Betaseed & Diploid resistant & Rzrz \\
SS-781R & Spreckels & Diploid segregating & Rzrz:rzrz \\
Rival & Holly & Diploid resistant & Rzrz \\
HM7072 & Novartis & Diploid resistant & Rzrz \\
Beta4038R & Betaseed & Triploid resistant & Rzrzrz \\
6921H50 & USDA-ARS & Diploid segregating & Beta maritima hybrid \\
\hline
\end{tabular}

Table 2. Triple-antibody sandwich enzyme-linked immunosorbent assay (TAS-ELISA) readings for beet necrotic yellow vein (BNYVV) and beet soilborne mosaic (BSBMV) viruses with BNYVV antiseray

\begin{tabular}{llc}
\hline Sample source & Viral infection & Absorbance $\left(\boldsymbol{A}_{\mathbf{4 0 5 n m}}\right)^{\mathbf{z}}$ \\
\hline Sugar beet roots (Beta vulgaris) & BNYVV & 2.227 \\
B. macrocarpa leaf tissue & BNYVV & 2.770 \\
B. macrocarpa leaf tissue & BSBMV-TX & 0.127 \\
B. macrocarpa leaf tissue & BSBMV-MN & 0.132 \\
Sugar beet roots & Healthy & 0.153 \\
B. macrocarpa & Healthy & 0.127 \\
\hline
\end{tabular}

${ }^{y}$ Polyclonal antiserum (trapping) and monoclonal antibodies (detecting) to BNYVV were used in TASELISA in preliminary tests for specificity to BNYVV.

${ }^{\mathrm{z}}$ Average of at least two wells. Tests were conducted in a greenhouse.

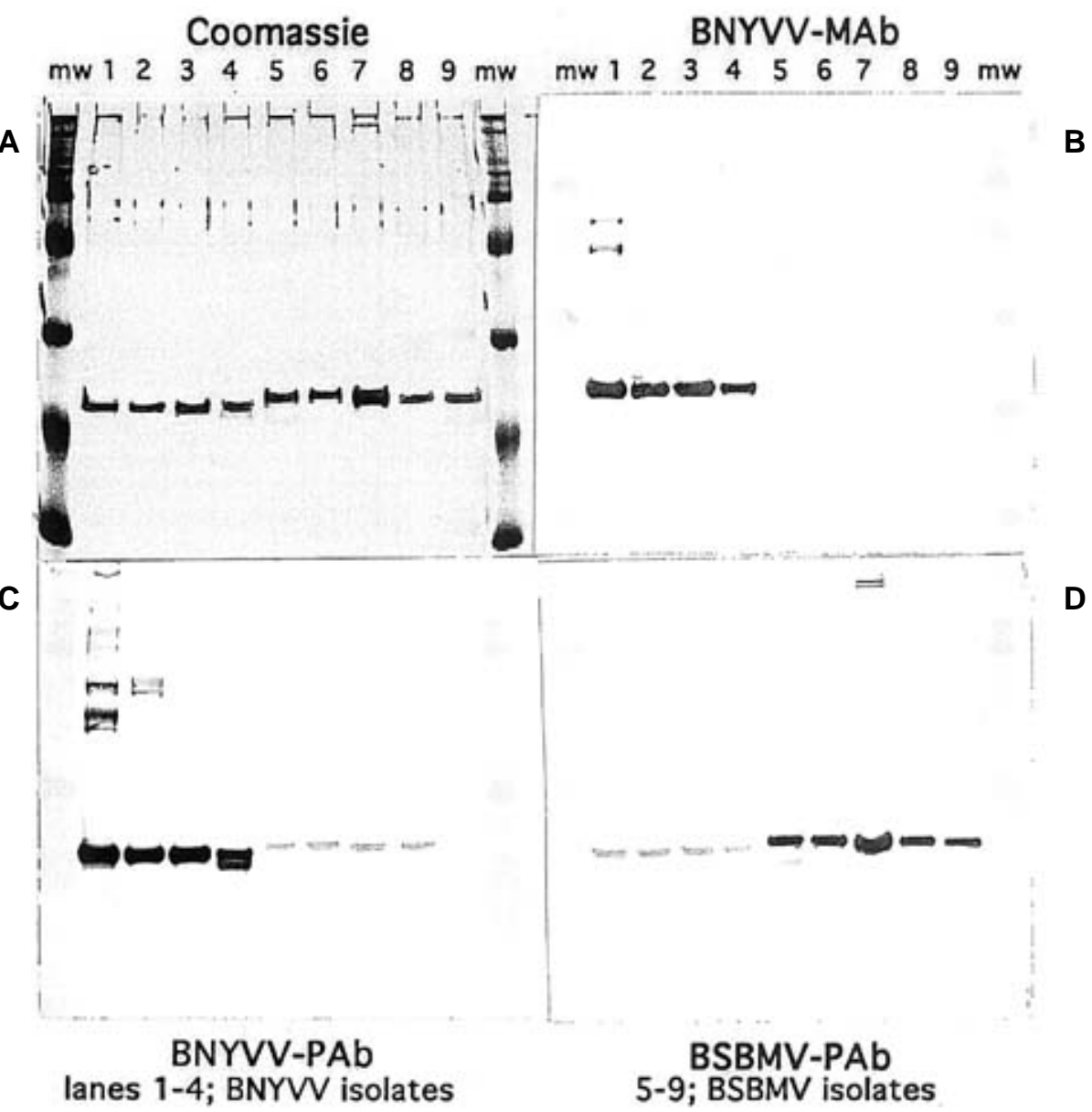

Fig. 1. Sodium dodecyl sulfate-polyacrylamide gel electrophoresis (SDS-PAGE) and corresponding western blot analysis of beet necrotic yellow vein virus (BNYVV, lanes 1 through 4) and beet soilborne mosaic virus (BSBMV, lanes 5 through 9) isolates. (A) Coomassie-stained gel with purified virus preparations of BNYVV and BSBMV; (B) western blot with a monoclonal antibody (MAb) to BNYVV; (C) western blot with polyclonal antiserum (PAb) to BNYVV; and (D) PAb to BSBMV. Lanes 1 through 4; BNYVV isolates from California, Nebraska, Colorado, and Minnesota, respectively. Lanes 5 and 6, BSBMV isolates from Texas; lane 7, isolate from Nebraska; lane 8, isolate from Colorado; and lane 9, isolate from Minnesota. The Coomassie gel shows the molecular mass of the $\mathrm{BNYVV}$ isolates at $\approx 22 \mathrm{kDa}$ and the BSBMV isolates at $\approx 24 \mathrm{kDa}$. The western blots show specificity for BNYVV with the BNYVV MAb and reciprocal cross-reactivity between BNYVV and BSBMV with their respective PAbs. 
studies showed a clear relationship between virus concentrations in BNYVV-infected plants and absorbance values obtained in ELISA (17,21). Preliminary TAS-ELISA tests test for BNYVV (Table 2).

Polyclonal antiserum used as the trapping antibody was made from the BNYVV CP expressed in vitro (provided by K. Richards). The pETH plasmid expressing the CP was identified by western blot assays and used to transform the appropriate host, Escherichia coli strain BL21DE3pLysS, for expression according to Studier et al. (20). An insoluble fusion protein of $\approx 22 \mathrm{kDa}$ was overexpressed and purified by sodium dodecyl sulfate-polyacrylamide gel electrophoresis as previously described (25). Antiserum was prepared in rabbits by Berkeley Antibodies (Richmond, CA). The antiserum was used to coat microtiter plates (Dynatech, Chantilly, VA) at a 1:1,000 dilution in coating buffer $(0.05 \mathrm{M}$ sodium carbonate, $\mathrm{pH}$ 9.6).

Plant samples consisted of fibrous lateral roots scraped from each beet and added to $2 \mathrm{ml}$ of extraction buffer (phosphate-buffered saline, $\mathrm{pH} 7.2$, with $0.5 \%$ Tween 20 and $0.4 \%$ dry milk powder). Root tissues were macerated in sample-extraction bags with a hand-held roller press (Agdia). Expressed sap was added as paired wells to plates at $150 \mu \mathrm{l}$ per well. A list of computer-generated random numbers was used to determine the placement of the 576 test samples per harvest on $23 \mathrm{mi}-$ crotiter plates. Each plate also contained paired wells with (i) sample buffer alone; tissues in sugar beet (B. vulgaris); (iii) noninoculated $B$. macrocarpa (B. vulgaris subsp. maritima var. macrocarpa) leaf tissue; and (iv) BNYVV systemically infected B. macrocarpa leaf tissue (Table $3)$.

The BNYVV monoclonal antibody used for detection and the goat-anti-mouse immunoglobulin G-alkaline phosphatase conjugate were provided by Agdia and used accordwere used to confirm the specificity of the (ii) rhizomania-diseased and healthy root

ing to instructions. Absorbance readings $\left(A_{405 \mathrm{~nm}}\right)$ were made at 15 -min intervals for $2 \mathrm{~h}$ with a microplate reader (EL312e, BioTek, Winooski, VT).

Field trials. Field trials were conducted at the USDA-ARS, U.S. Agricultural Research Station, Salinas, where rhizomania tests have been conducted on infested land since 1984. The primary test studied (test A) was planted on 1 May 1997 in a splitplot design, in which harvest dates were the main plot, with eight cultivars (subplots) randomized into three harvest dates (14 July, 18 August, 20 October) and eight replicate plots. The plots were over-seeded, and plants were thinned at the two-leaf stage to a spacing of $16 \mathrm{~cm}$ between single plants. Standard best cultural practices were used, including weed, insect, and disease control measures. Sprinkler irrigation was used throughout the season at weekly intervals to field capacity to enhance rhizomania development. Observations at Salinas over many years have suggested that BNYVV levels, as measured by ELISA, vary depending on timing of irrigation (wettingdrying periods). For this reason, we felt it necessary to measure virus content in the field trial at each harvest 3 days after the most recent irrigation. For the first two harvests, plots were $2.3 \mathrm{~m}$ long with 0.6 $\mathrm{m}$ alleys. Excluding end plants, nine beets were randomly harvested within each plot. For the third harvest, plots were longer $(5.2 \mathrm{~m})$ to accommodate both laboratory and yield evaluations. Plots were adjusted to $3.6 \mathrm{~m}$ after consecutive individual plant harvests from $1.6 \mathrm{~m}$ from one end of each plot.

In each of the three harvests, the 9 randomly selected beets from each plot (72 plants per cultivar; 576 plants per harvest date) were dug by hand, topped just above the lowest leaf scar, and washed free of soil particles. Fibrous roots were scraped from each beet, and $0.5 \mathrm{~g}$ was taken for the ELISA test. In the first harvest, because of the small size of the beets, only TASELISA was done. In the second and third

Table 3. Triple-antibody sandwich enzyme-linked immunosorbent assay (TAS-ELISA) absorbance readings $\left(A_{405 \mathrm{~nm}}\right)$ of beet necrotic yellow vein (BNYVV) by cultivar, harvest date, and cultivar-date (test $\left.\mathrm{A}\right)^{\mathrm{y}, \mathrm{z}}$

\begin{tabular}{llllll}
\hline Cultivar & Genotype & 14 July & 18 August & 22 October & Mean \\
\cline { 1 - 2 } & $r z r z$ & $0.947 \mathrm{a}$ & $0.365 \mathrm{c}$ & $0.226 \mathrm{e}-\mathrm{g}$ & $0.513 \mathrm{~b}$ \\
KWS6770 & $r z r z r z$ & $1.024 \mathrm{a}$ & $0.414 \mathrm{c}$ & $0.341 \mathrm{~cd}$ & $0.593 \mathrm{a}$ \\
Beta4776R & $R z r z$ & $0.257 \mathrm{~d}-\mathrm{f}$ & $0.150 \mathrm{~g}-\mathrm{i}$ & $0.117 \mathrm{hi}$ & $0.175 \mathrm{de}$ \\
SS-781R & $R z r z: r z r z$ & $0.343 \mathrm{~cd}$ & $0.164 \mathrm{f}-\mathrm{i}$ & $0.140 \mathrm{~g}-\mathrm{i}$ & $0.216 \mathrm{de}$ \\
Rival & $R z r z$ & $0.316 \mathrm{c}-\mathrm{e}$ & $0.138 \mathrm{~g}-\mathrm{i}$ & $0.128 \mathrm{~g}-\mathrm{i}$ & $0.195 \mathrm{de}$ \\
HM7072 & $R z r z$ & $0.218 \mathrm{e}-\mathrm{g}$ & $0.111 \mathrm{i}$ & $0.138 \mathrm{~g}-\mathrm{i}$ & $0.156 \mathrm{e}$ \\
Beta4038R & $R z r z r z$ & $0.562 \mathrm{~b}$ & $0.220 \mathrm{e}-\mathrm{g}$ & $0.212 \mathrm{f}-\mathrm{h}$ & $0.332 \mathrm{c}$ \\
6921H50 & Unknown & $0.356 \mathrm{~cd}$ & $0.192 \mathrm{f}-\mathrm{i}$ & $0.155 \mathrm{~g}-\mathrm{i}$ & $0.234 \mathrm{~d}$ \\
$\quad$ Mean & & $0.503 \mathrm{a}$ & $0.219 \mathrm{~b}$ & $0.182 \mathrm{~b}$ & 0.302 \\
Healthy sugar beet root & & 0.105 & 0.096 & 0.102 & 0.101 \\
BNYVV-infected sugar beet root & 0.513 & 0.372 & 0.482 & 0.456 \\
Healthy B. macrocarpa leaf & 0.106 & 0.098 & 0.103 & 0.103 \\
BNYVV-infected B. macrocarpa leaf & 1.654 & 1.031 & 2.345 & 1.677 \\
\hline
\end{tabular}

${ }^{y}$ Values represent an average of two wells from eight replicate plots of nine beets each.

${ }^{\mathrm{z}}$ Within each column, mean values followed by the same letter are not significantly different $(P=$ $0.05)$. harvests, TAS-ELISA tests were done, taproots were individually weighed, and each beet root was scored according to a rhizomania disease index (DI). The root score index was adapted, using a scale of 0 to 9 , to comply with the international scale for sugar beet germ plasm evaluation (Fig. 2): $0=$ no visual symptoms; 1 = very resistant (nearly normal taproot and minor bearding); 3 = resistant (taproot slightly to moderately constricted, moderate bearding and taproot discoloration); 5 = intermediate (taproot wineglass shaped, feeder roots bearded, taproot discolored); 7 = susceptible (severe bearding and stunting, taproot destroyed); and $9=$ highly susceptible (beet death). Beets were harvested mechanically at the end of the third harvest, weighed, and run through a standard sugar laboratory to measure sucrose concentration. Sugar yield was calculated based on plot weight and sucrose concentration.

In adjacent identical field trials, the eight cultivars were evaluated for root yield, DI, percent sucrose, and sugar yield under moderate or severe disease pressures and cultural practices. The trials (B, C, D, and E) were randomized complete block designs with eight replicates. One-row plots were $72 \mathrm{~cm}$ wide and 6.1 or $6.4 \mathrm{~m}$ long. Test $\mathrm{E}$ was hand-harvested and topped, and roots were scored for rhizomania based on the DI scale. Classes 0 to 3 were considered resistant, and classes 4 to 9 were considered susceptible. After root scoring, all beets were bulked by plot, washed, weighed, and run through the sugar analysis laboratory. The other field trials were harvested mechanically for yield and sugar analysis, so individual beets were not scored for reactions to rhizomania.

Data analysis. Data obtained from individual plants (576 plants per harvest) within each plot of test A on three harvest dates were averaged and used for statistical analyses. Data consisted of ELISA values, DI, root yield, percent sucrose, and sugar yield. Initially all data were analyzed for splitplot analysis at Salinas by MSTAT, in which harvest dates were the main plots. Heterogeneity of variance occurred for optical densities measured by TAS-ELISA and individual root weights. Analyses of traits were done with PROC MIXED (SAS Institute Inc., Cary, NC). Data were transformed by natural $\operatorname{logs}$ that alleviated heterogeneity for root weights and greatly reduced heterogeneity for optical densities. For optical densities and root weights, means and confidence intervals were transformed back to the original scale. For correlations among absorbance $\left(A_{405 \mathrm{~nm}}\right)$, absorbance of test sample divided by absorbance of healthy roots $(\mathrm{abs} / \mathrm{H})$, root score, root weight, percent sucrose, and sugar yield, date-cultivar means were used (Table 4). Data obtained from individual randomized complete block tests (B, C, D, and E) to evaluate the performance of the eight cultivars also were analyzed by MSTAT. 


\section{RESULTS}

Serological analysis. The TAS-ELISA test modified for this study produced no background cross-reaction with healthy samples or other furoviruses of sugar beet, in particular, isolates of BSBMV from Texas and Minnesota (Table 2). A wide range of readings was observed with different BNYVV samples at various serial dilutions, thus enabling measurement of differences in BNYVV content among resistant and susceptible sugar beet cultivars.

Differences in absorbance values for BNYVV measured by TAS-ELISA among eight cultivars were closely correlated to the dosage and frequency of the $R z$ allele that conditions resistance to BNYVV (Table 3 ). Diploid Rzrz hybrid Beta4776R had a significantly lower value than the similar triploid Rzrzrz hybrid Beta4038R. Cultivars that segregated (Rzrz:rzrz; i.e., SS-781R and 6921H50) had higher absorbance values than the uniformly resistant $R z r z$ hybrids Beta4776R and HM7072.

Field trials. For all cultivars, differences were observed among harvest dates, with progressively lower absorbance values mea- sured as the season progressed, particularly from 14 July to 18 August. A highly significant cultivar-harvest date interaction occurred. The interaction can be explained largely by the rate and magnitude of decrease in absorbance values for susceptible cultivars compared with resistant cultivars. Absorbance readings for the 14 July harvest clearly discriminated differences in cultivar reactions more than in subsequent harvests (Table 3). Differences in cultivars, based only on TAS-ELISA results from the third harvest date, did not show allelic dosage and frequency effects as clearly as in the first two harvests.
There were close correlations between variables used to evaluate reactions to rhizomania, including absorbance $\left(A_{405 \mathrm{~nm}}\right)$, abs $/ \mathrm{H}$, root score, and root weight (Table 4). There was a nearly perfect correlation between absorbance of test samples and absorbance of test samples divided by those of healthy roots grown in pasteurized soil $(\mathrm{abs} / \mathrm{H})$, indicating extremely low background reactions and very little plate-toplate variability and experimental error. The highly significant positive correlations between abs/H values and root scores $(r=0.87$ and 0.95 for dates 2 and 3 , respectively) showed that visual dis-

Table 4. Coefficients of correlation among treatment means for two harvest dates ${ }^{\mathrm{y}}$

\begin{tabular}{lcccc}
\hline & $\begin{array}{c}\text { Absorbance } \\
\left(\boldsymbol{A}_{\mathbf{4 0 5} \mathbf{n m}}\right)\end{array}$ & $\begin{array}{c}\text { Absorbance/ } \\
\text { healthy }\end{array}$ & Root score & Root weight (g) \\
\hline Absorbance & $\ldots$ & $0.99^{* *}$ & $0.87^{* *}$ & $-0.89^{* *}$ \\
Absorbance/healthy & $0.99^{* *}$ & $\ldots$ & $0.87^{* *}$ & $-0.89^{* *}$ \\
Root score & $0.95^{* *}$ & $0.95^{* *}$ & $\ldots$ & $-0.89^{* *}$ \\
Root weight & $-0.76^{*}$ & $-0.76^{*}$ & $-0.87^{* *}$ & $\ldots$ \\
\hline
\end{tabular}

y The correlations for harvest date two (18 August) are above the diagonal, and those for date three (22 October) are below the diagonal. * and $* *$ indicate significance at $P=0.05$ and 0.01 , respectively.

z Absorbance $\left(A_{405 \mathrm{~nm}}\right)$ for test samples divided by absorbance for healthy root samples.
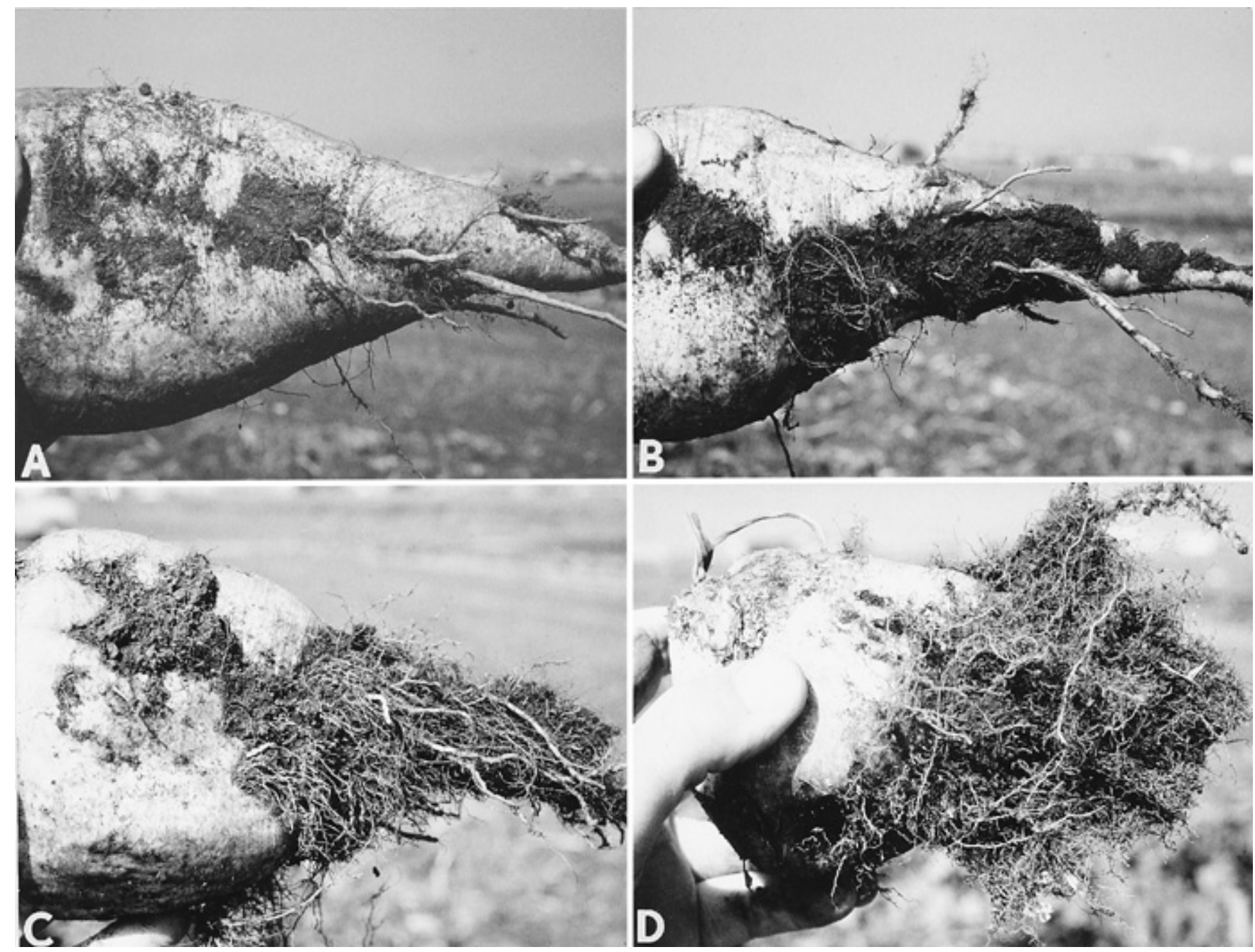

Fig. 2. The rhizomania disease index was adapted, using a scale of 0 to 9 , to comply with the international scale for sugar beet germ plasm evaluation: $0=$ immunity (no visual symptoms; not shown); $1=$ very resistant $(\mathbf{A}) ; 3=$ resistant $(\mathbf{B}) ; 5=$ intermediate $(\mathbf{C}) ; 7=$ susceptible $(\mathbf{D})$; and $9=$ highly susceptible (beet death; not shown). 
ease reaction scores for roots were highly correlated with virus concentration.

Correlations between abs/ $\mathrm{H}$ and root weight $(r=-0.89$ and -0.76 for harvest dates 2 and 3, respectively) were negative (Table 4). Root weights and disease scores also were highly inversely correlated ( $r=$ -0.91 and -0.87 at $P=0.01$ for harvest dates 2 and 3, respectively). Also, as shown by harvest date results, virus levels decreased through the course of the season.

Field tests $\mathrm{B}$ and $\mathrm{C}$ were intended to be rhizomania-free, but at harvest, it was obvious based on root symptoms that these fields were moderately infested. Thus, no rhizomania-free test was available for comparison. In all tests, the two susceptible checks had significantly lower yields than more resistant cultivars (Table 5). Under moderate rhizomania conditions, yield differences were small $(\approx 4 \%)$ between the two cultivars and not significantly different, whereas under severe conditions the differences were larger $(\approx 13 \%)$ and significant. In all tests, advanced hybrid Beta4776R tended to have the highest root and sugar yields. Roots from test $\mathrm{E}$ were scored individually at harvest for reactions to rhizomania. There was a good correlation and comparable ranking of root score means for cultivars across tests $\mathrm{E}$ and $\mathrm{A}$ for the corresponding harvest date (date 3 for test A). These tests support the data and interpretations made for test A.

Three cultivars with known genotypes were chosen as representatives of distinct allelic dosages to determine the association between $R z$ allele quantity and frequency and the three variables measured in our study, including absorbance, root score, and root weight (Fig. 3). The genotypes of the cultivars were uniformly susceptible ( $r z r z r z$, KWS6770), diploid resistant (Rzrz, Beta4776R), and triploid resistant (Rzrzrz, Beta4038R). A strong negative correlation was found be- tween increasing dosage of the $R z$ allele and absorbance and root scores, but a positive correlation was found with root weight.

\section{DISCUSSION}

Our study shows that the current field evaluation system used in the United States by industry and public agencies is equally suitable for more laborious and expensive evaluation by ELISA. Using cultivars that are important in United States beet production, we have shown that ELISA readings are significantly correlated with root score and negatively correlated with root weight and percent sucrose. The readings and evaluations, when compared against a range of rhizomania susceptible and resistant cultivars, indicate the data can be useful for predicting the genetic background of cultivars about which little is known. Root weights and visual scoring usually are made much more easily in a breeding or testing program than absorbance measurements in ELISA tests.

The agronomic data for test A appeared to be valid and consistently measured and differentiated cultivar reactions to BNYVV. There was high correlation between the dosage and frequency of the $R z$ allele and BNYVV levels in lateral roots when measured by TAS-ELISA. Within hybrids such as SS-781R, we expected and found that fully susceptible ( $r z r z)$ segregants increased mean virus content. When individual plant ELISA and visual and yield ratings were examined and taken into account for hybrids such as SS-781R, the plants that were probably $R z r z$ had values similar to Beta4776R, and putative $r z r z$ plants had values similar to USH11 or KWS6770. Comparison of sugar yields for Beta4776R (Rzrz) and Beta4038R (Rzrzrz) under two moderate disease tests (B and $\mathrm{C}$ ) and two severe disease tests (D and E) suggested that the level of resistance conditioned by allelic dos- age was reflected in root yield, percent sucrose, and sugar yield.

Of more interest was the relationship between allele dosage and virus levels. It was clear that in terms of virus levels $R z r z$ $<R z r z r z<r z r z \approx r z r z r z$. Incomplete dominance (gene dose) is a common phenomenon for host-plant resistance to viruses. Fraser (9) found that many virus resistances inherited at a single locus are expressed in an incompletely dominant manner. Pelsey and Merdinoglu (18) showed that $R z$ is inherited as incompletely dominant when measured based on virus content of greenhousegrown plants in standardized inoculum tests.

Our results suggest that a further incremental increase in resistance may be achievable in sugar beet hybrids. It is likely that the $R z R z$ genotype would contain less virus than the Rzrz or Rzrzrz genotypes currently grown. It would benefit breeders, therefore, to develop homozygous $R z R z$ parental lines for all components of commercial hybrid cultivars, because $R z R z$ cultivars could provide a higher level of protection against rhizomania and certainly could be important in limiting inoculum buildup in soils. The lag in use of only $R z R z$ parental line components reflects the time and effort necessary to incorporate and fix a single gene into all component lines and advanced breeding materials. Experimental, homozygous resistant lines are available and will be included in future research similar to the current study.

Correct diagnosis of BNYVV can be confounded by low levels of cross-reactivity with other furoviruses, in particular BSBMV, as has been demonstrated previously (23). In addition, levels of BNYVV, which are dependent on production of viruliferous $P$. betae zoospores, vary in sugar beets during the growing season in rhizomania-infested fields. Our study demonstrates what has been observed over the years by researchers, that levels of BNYVV can change

Table 5. Performance of sugar beet cultivars under different rhizomania (Rhizo.) severities ${ }^{\mathrm{W}}$

\begin{tabular}{|c|c|c|c|c|c|c|c|c|c|c|c|c|c|c|}
\hline \multirow[b]{3}{*}{ Cultivar } & \multicolumn{3}{|c|}{ Test $\mathbf{B}^{\mathbf{x}}$} & \multicolumn{3}{|c|}{ Test $C^{x}$} & \multicolumn{3}{|c|}{ Test $D^{y}$} & \multicolumn{3}{|c|}{ Test $\mathbf{E}^{\mathbf{y}}$} & & \\
\hline & \multirow{2}{*}{$\begin{array}{c}\text { SY } \\
\text { (kg/ha) }\end{array}$} & \multirow{2}{*}{$\begin{array}{c}\text { RY } \\
\text { (t/ha) }\end{array}$} & \multirow{2}{*}{$\begin{array}{c}\text { Sucr. } \\
(\%)\end{array}$} & \multirow{2}{*}{$\begin{array}{c}\text { SY } \\
\text { (kg/ha) }\end{array}$} & \multirow{2}{*}{$\begin{array}{c}\text { RY } \\
\text { (t/ha) }\end{array}$} & \multirow{2}{*}{$\begin{array}{c}\text { Sucr. } \\
(\%)\end{array}$} & \multirow{2}{*}{$\begin{array}{c}\text { SY } \\
\text { (kg/ha) }\end{array}$} & \multirow{2}{*}{$\begin{array}{c}\text { RY } \\
\text { (t/ha) }\end{array}$} & \multirow{2}{*}{$\begin{array}{c}\text { Sucr. } \\
(\%)\end{array}$} & \multirow{2}{*}{$\begin{array}{c}\text { SY } \\
\text { (kg/ha) }\end{array}$} & \multirow{2}{*}{$\begin{array}{c}\text { RY } \\
\text { (t/ha) }\end{array}$} & \multirow{2}{*}{$\begin{array}{c}\text { Sucr. } \\
(\%)\end{array}$} & \multicolumn{2}{|c|}{ Rhizo. reaction ${ }^{2}$} \\
\hline & & & & & & & & & & & & & DI & $\% \mathbf{R}$ \\
\hline \multicolumn{15}{|l|}{ Susceptible check } \\
\hline USH11 & 4,938 & 51.6 & 9.5 & 5,824 & 56.6 & 10.3 & 5,449 & 47.6 & 11.0 & 3,528 & 30.3 & 11.7 & 4.6 & 36.0 \\
\hline KWS6770 & 5,406 & 50.7 & 10.6 & 8,356 & 64.0 & 13.1 & 6,947 & 53.7 & 13.0 & 4,735 & 33.3 & 14.3 & 4.5 & 38.9 \\
\hline \multicolumn{15}{|l|}{ Resistant hybrid } \\
\hline Beta4776R & 10,848 & 81.2 & 13.4 & 13,669 & 93.7 & 14.6 & 12,333 & 84.9 & 14.5 & 11,146 & 68.0 & 16.4 & 2.4 & 94.9 \\
\hline SS-781R & 8,692 & 72.5 & 11.9 & 10,948 & 81.1 & 13.5 & 8,838 & 65.3 & 13.6 & 6,692 & 48.1 & 14.0 & 3.1 & 77.1 \\
\hline Rival & 8,789 & 66.1 & 13.3 & 11,533 & 80.9 & 14.3 & 8,943 & 63.4 & 14.2 & 8,413 & 54.1 & 15.6 & 2.8 & 83.7 \\
\hline HM7072 & 10,294 & 69.4 & 14.8 & 12,955 & 82.1 & 15.8 & 10,820 & 68.6 & 15.7 & 8,989 & 53.5 & 16.8 & 3.2 & 76.9 \\
\hline Beta4038R & 10,180 & 72.5 & 14.1 & 13,310 & 84.6 & 15.7 & 10,961 & 68.0 & 16.2 & 9,454 & 54.7 & 17.3 & 3.5 & 64.9 \\
\hline \multicolumn{15}{|c|}{ USDA exp. hybrid } \\
\hline $6921 \mathrm{H} 50$ & 9,524 & 76.9 & 12.3 & 11,520 & 84.8 & 13.6 & 10,478 & 79.0 & 13.3 & 9,032 & 64.8 & 14.0 & 2.9 & 81.7 \\
\hline $\operatorname{LSD}(P=0.05)$ & 946 & 6.0 & 0.8 & 1,017 & 6.1 & 0.6 & 1,117 & 7.0 & 0.8 & 762 & 5.0 & 0.7 & 0.4 & 10.3 \\
\hline
\end{tabular}

${ }^{\mathrm{w}} \mathrm{SY}=$ sugar yield; RY = root yield; Sucr. = sucrose.

x Tests B and C were grown at Salinas, CA, under moderate rhizomania conditions. Sown 10 April 1997; harvested 2 October 1997 and 29 September 1997, respectively. Eight replicate plots in a randomized complete block design.

y Tests D and E were grown at Salinas under severe rhizomania conditions (one-row plots, $6.1 \mathrm{~m}$ long) and adjacent to test A. Test D was planted 30 April 1997 and harvested 29 October. Test E was planted 1 May 1997 and harvested 20 October 1997.

${ }^{\mathrm{z}} \mathrm{DI}=$ disease index: individual roots were scored (test E) at harvest on a scale of 0 (no symptoms) to 9 (death). \% R = percent resistance (test E): classes 0 to 3 were considered resistant. 
during a growing season. As the season progressed in our study, levels of BNYVV continued to decline when measured by TAS-ELISA, in spite of the presence of well-developed rhizomania symptoms and regardless of cultivar. This could be due to several unknown factors, including plant susceptibility as it declines with age, younger plants that are more susceptible than older ones, and climatic conditions during the season.

Our results confirm observations made over many years at Salinas that late-summer BNYVV titer values do not seem to reflect cultivar reactions. These results suggest that because of the effects of plant age, environmental factors, and sampling techniques timeliness is an important consideration in use of ELISA to evaluate cultivar reactions to BNYVV when testing fieldgrown beets directly. Because sugar beet is not a good systemic host for BNYVV, as evidenced by the extremely low occurrence of systemic symptoms and restriction of BNYVV to the area of proliferated roots (10), the level of BNYVV in sugar beet roots depends on the activity of the vector, which in turn depends on soil temperature and moisture and beet root exudates.
In the absence of overriding effects of other diseases and cultivar influences, our study shows that breeders can be fairly confident of measuring cultivar reactions to rhizomania by scoring and weighing fieldgrown materials. The negative correlations observed between absorbance and root weight suggest that high virus concentration or rhizomania reactions can be predicted by taproot weight when rhizomania is present.

In addition to the $R z$ (Holly source) resistance factor, other sources of resistance to rhizomania have been found (11). Some sources appear to be the $R z$ allele, but others appear to be different from $R z(8,19)$. At least one source, when tested under severe rhizomania conditions, provided better protection than $R z(11,15)$. Tests are underway to map each of the sources of resistance, determine their allelism, and identify molecular markers $(8,18,19)$. If additional major genes at different loci are distinguished, they may reduce the vulnerability of $R z$. In addition, preliminary evidence suggests that one or more genes condition lower levels of BNYVV than does $R z$. With markerassisted selection, it may become possible to combine multiple resistance factors into individual cultivars to obtain improved re- sistance to rhizomania, further decrease BNYVV inoculum production (17), and provide more durable resistance.

\section{ACKNOWLEDGMENTS}

We thank T. Gottwald and B. Mackey for their advice and assistance regarding statistical analyses.

\section{LITERATURE CITED}

1. Abe, H., and Tamada, T. 1986. Association of beet necrotic yellow vein virus with isolates of Polymyxa betae Keskin. Ann. Phytopathol. Soc. Jpn. 52:235-247.

2. Abe, H., and Ui, T. 1986. Host range of Polymyxa betae Keskin strains in rhizomania-infested soils of sugar beet fields in Japan. Ann. Phytopathol. Soc. Jpn. 52:394-403.

3. Asher, M. J. C., and Kerr, S. 1996. Rhizomania: Progress with resistant varieties. $\mathrm{Br}$. Sugar Beet Rev. 64:19-22.

4. Asher, M. J. C., Mutasa-Goettgens, E. S., and Chwarszczynska, D. M. 1997. Rhizomania: The role of vectors and virus resistance in sugar beet. Page 35 in: Proc. 60th I.I.R.B. Congr Imprimerie J. Duculot. Brussels, Belgium.

5. Barr, D. J. S. 1992. Evolution and kingdoms of organisms from the perspective of a mycologist. Mycologia 84:1-11.

6. Duffus, J. E., and Liu, H. Y. 1987. First report of rhizomania of sugar beet from Texas. Plant Dis. 71:557.

7. Duffus, J. E., Whitney, E. D., Larson, R. C., Liu, H. Y., and Lewellen, R. T. 1984. First report in Western Hemisphere of rhizomania of sugar
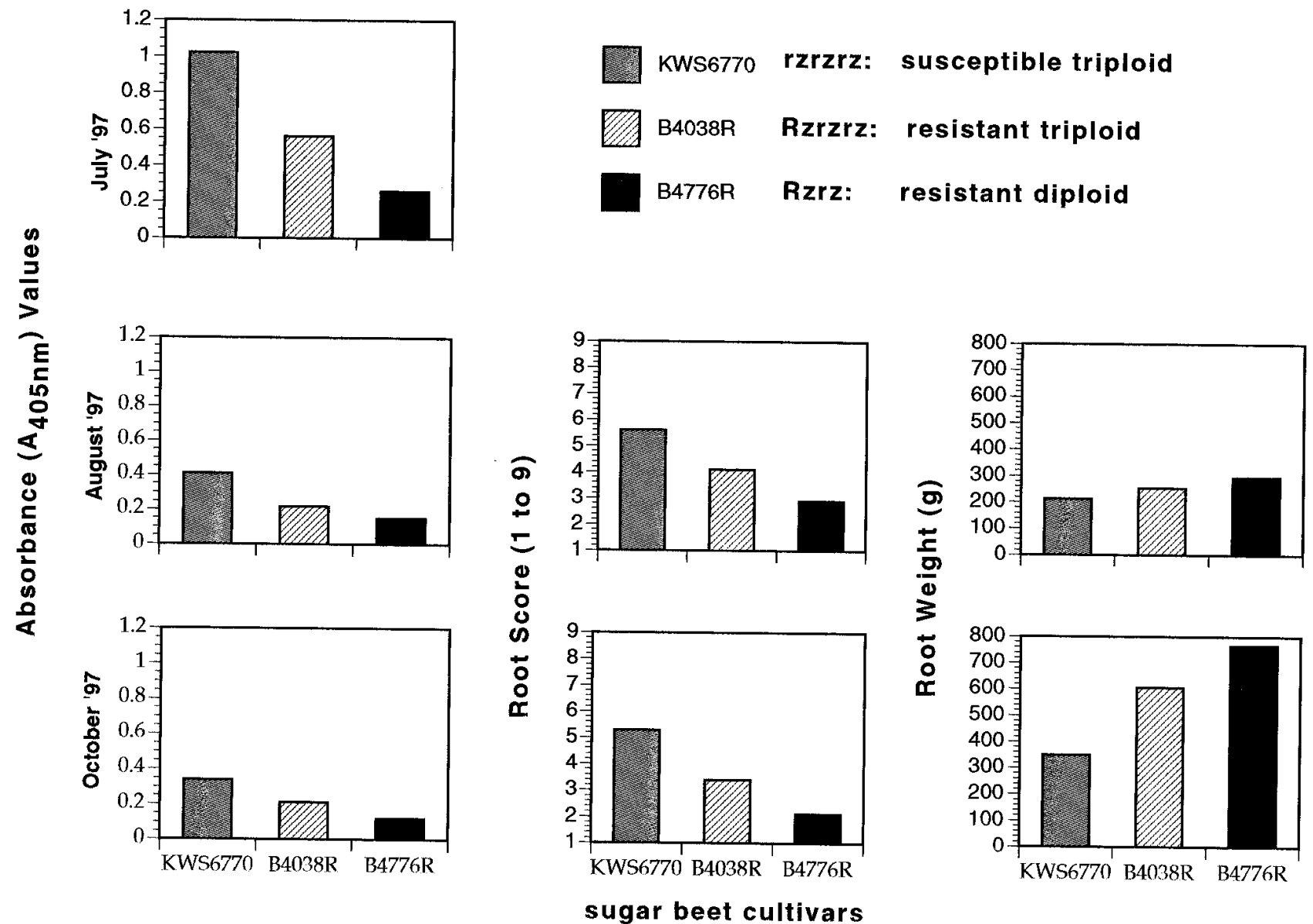

Fig. 3. Three sugar beet cultivars that range from uniformly susceptible (rzrzrz, KWS6770) to resistant (diploid, Rzrz, Beta4776R and triploid, Rzrzrz, Beta4038R) for beet necrotic yellow vein virus (BNYVV), illustrating the correlation between dosage of the $R z$ allele and three variables: absorbance in triple-antibody sandwich enzyme-linked immunosorbent assay for BNYVV, rhizomania root score, and root weight. A negative correlation was observed between increasing dosage of the $R z$ allele and absorbance values for BNYVV for the three harvest dates. For the last two harvest dates, a negative correlation was observed between allelic dosage and root score, whereas it was positive between allelic dosage and root weight. 
beet caused by beet necrotic yellow vein virus. Plant Dis. 68:251.

8. Francis, S. A., Redfearn, M., Chwarszczynska, D. M., Asher, M. J. C., and Lewellen, R. T. 1998. Use of molecular markers in breeding for disease resistance in sugar beet (Beta vulgaris L.). Aspects Appl. Biol. 52:279-285.

9. Fraser, R. S. S. 1987. Genetics of plant resistance to viruses. Pages 6-22 in: Plant Resistance to Viruses. Ciba Foundation Symp. 133. John Wiley \& Sons, Chichester, England.

10. Kaufmann, A., Koenig, R., and Lesemann, D. E. 1992. Tissue print-immunoblotting reveals an uneven distribution of beet necrotic yellow vein and beet soil-borne viruses in sugarbeets. Arch. Virol. 126:329-335.

11. Lewellen, R. T. 1995. Performance of nearisolines of sugarbeet with resistance to rhizomania from different sources. Pages 83-91 in: Proc. 58th I.I.R.B Congr. Imprimerie J. Duculot. Brussels, Belgium.

12. Lewellen, R. T., and Biancardi, E. 1990. Breeding and performance of rhizomania resistant sugarbeet. Pages 69-87 in: Proc. 53rd I.I.R.B. Winter Congr. Imprimerie J. Duculot. Brussels, Belgium.

13. Lewellen, R. T., Skoyen, I. O., and A. W. Erichsen. 1987. Breeding sugarbeet for resistance to rhizomania: Evaluation of host-plant reactions and selection for and inheritance of resistance. Pages 139-156 in: Proc. 50th I.I.R.B. Winter Congr. Imprimerie J. Duculot. Brussels, Belgium.
14. Lewellen, R. T., and Whitney, E. D. 1993. Registration of germplasm lines developed from composite crosses of sugarbeet $\times$ Beta maritima. Crop Sci. 33:882-883.

15. Lewellen, R. T., and Wrona, A. F. 1997. Solarization and host-plant resistance as alternatives to soil fumigation to control rhizomania of sugarbeet. Pages 189-201 in: Proc. 60th I.I.R.B. Congress. Imprimerie J. Duculot. Brussels, Belgium.

16. Margulis, L., and Schwartz, K. V. 1988. Plasmodiophoromycota. Pages 136-137 in: Five Kingdoms. W. H. Freeman \& Co., New York.

17. Obermeier, C. 1998. DNA-gestützte Nachweisverfahren für den Virusübertragenden Bodenpilz Polymyxa betae und ihr Einsatz im Rizomania-Resistenztest bei Zuckerrüben. Ph.D. thesis. Technischen Universitat Carolo-Wilhelmina zu Braunschweig, Germany.

18. Pelsey, F., and Merdinoglu, D. 1996. Identification and mapping of random amplified polymorphic DNA markers linked to a rhizomania resistance gene in sugar beet (Beta vulgaris L.) by bulked segregant analysis. Plant Breeding 115:371-377.

19. Sholten, O. E., Klein-Lankhorst, R. M., Esselink, D. G., DeBock, T. S. M., and Lange, W. 1997. Identification and mapping of random amplified polymorphic DNA (RAPD) markers linked to resistance against beet necrotic yellow vein virus (BNYVV) in Beta accessions. Theor. Appl. Genet. 94:123-130.

20. Studier, F. W., Rosenberg, A. H., Dunn, J. J., and Dubendorff, J. W. 1990. Use of T7RNA polymerase to direct expression of cloned genes. Methods Enzymol. 185:60-68.

21. Tuitert, G., Musters-Van Oorschot, P. M. S., and Hiejbroek, W. 1994. Effect of sugar beet cultivars with different levels of resistance to beet necrotic yellow vein virus on transmission of virus by Polymyxa betae. Eur. J. Plan Pathol. 100:201-220.

22. Wisler, G. C., Duffus, J. E., Liu, H.-Y., Kerr, E., and Gallian J. J. 1994. Incidence of two soilborne viruses of sugar beet in the USA. (Abstr.) Phytopathology 84:1171.

23. Wisler, G. C., Liu, H.-Y., and Duffus, J. E 1994. Beet necrotic yellow vein virus and its relationship to eight sugar beet furo-like viruses from the U.S.A. Plant Dis. 78:995-1001.

24. Wisler, G. C., Liu, H.-Y., Li, R. H., and Duffus, J. E. 1996. Comparative molecular analysis of several BNYVV- and BSBMV-related furoviruse infecting sugarbeet. Pages 53-56 in: Proc. 3rd Int. Work. Group Plant Viruses Fungal Vectors Beet Sugar Development Foundation, Denver, CO.

25. Wisler, G. C., Purcifull, D. E., and Hiebert, E. 1995. Characterization of the P1 protein of the zucchini yellow mosaic potyvirus. J. Gen. Virol. 76:37-45.

26. Wisler, G. C., Widner, J. N., Duffus, J. E. Liu, H.-Y., and Sears, J. L. 1997. A new report of Rhizomania and other furoviruses infecting sugar beet in Minnesota. Plant Dis. $81: 229$ 